

\section{INDICE}

EDITORIAL PERSONAL ÁMBITOS

Apresentação do monográfico. Abordagem qualitativa: olhares e práticas transdisciplinares nas ciências antropossociais

Presentation of the monograph. Qualitative approach: transdisciplinary views and practices in anthroposocial sciences

Ronaldo Nunes Linhares, António Pedro Costa

MONOGRAFICOS MONOGRAPHS

Identidades femininas na rede: as crianças falam!

Female identities on line: children can speak

Marta Maria Azevedo Queiroz

$12-31$

Transição de cuidados de enfermagem: ISBAR na promoção da segurança dos

doentes - revisão scoping

Transition of nursing care: ISBAR in promoting patient safety - scoping review

Ana Rita Esteves Figueiredo, Teresa Maria Ferreira dos Santos Potra, Pedro Ricardo Martins Bernardes Lucas

$32-48$

Integración de elementos cualitativos y cuantitativos en metodología observacional

Integration of qualitative and quantitative elements in observational methodology

M. Teresa Anguera, Angel Blanco-Villaseñor, José Luis Losada, Pedro Sánchez-Algarra

49-70

Atos educativos com oficines de ecografias: uma investigação otobiográfica

Educational acts at echographie's cineliers: an otobiographic research

Silas Borges Monteiro, Anaise Avila Severo

Actuación de las políticas: política como texto y política como discurso

Action of policies: policy as text and policy as discourse

Mónica Rocío Barón

88-104 


\section{ÁMBITOS PERSONALES PERSONAL ÁMBITOS}

Un retrato de la cultura local a través del Periodismo cultural. Análisis comparado de Sevilla y Porto Alegre

A portrait of the local culture through cultural Journalism. Comparative analysis of Seville and Porto Alegre

\section{ARTÍCULOS ARTICLES}

Microsociología del profesor universitario

Microsociology of an university professor

Antonio Fernández Vicente

La pobreza y el discurso de los mass media. Un estudio de la prensa local argentina

Poverty and mass media 's discourse. A study of the Argentine local press

María del Rosario Sanchez, Silvia London

La comunicación no verbal en las elecciones andaluzas de 2018. Comparativa de Susana Díaz y Teresa Rodríguez en el debate de RTVE

Non-verbal communication in the Andalusian municipal elections of 2018. Comparison of Susana Díaz and Teresa Rodríguez in the electoral RTVE debate

María Hernández Herrarte, Patricia Zamora-Martínez

El infoentretenimiento en la televisión de pago, Movistar+ y el canal \#0.

El uso transmedia de sus contenidos de humor

Infotainment on pay television, Movistar+ and channel \# 0 . The transmedia use of its humorous content

Metodología y formación docente cuestiones claves para la integración de las TIC en la educación

Methodology and teacher training as a key issue for ICTs integration in Education 


\section{RESEÑAS REVIEWS}

Aquelarre. Mujeres en la cultura de masas

Coven. Women in mass culture

Regla Ismaray Cabreja Piedra

216-220

Transición ecosocial y principios éticos en el periodismo: una guía para la comunicación de nuevas narrativas

The Eco-social transition and ethical principles in journalism: a guide for the communication of new narratives

Amanda Salazar Torres

Narrativas ecofeministas y mapa de transición ecosocial para medios de comunicación Eco-feminist narratives and ecosocial transition map for the media 


\title{
Identidades femininas na rede: as crianças falam!
}

\author{
Female identities on line: children can speak
}

\author{
Marta Maria Azevedo Queiroz, Universida de Federal do Piauí-UFPI. Campus \\ Universitário Ministro Petrônio Portella, S/N, Bairro Ininga, Teresina, Piauí, \\ Brasil, CEP: 64049-550. \\ profa.marta@hotmail.com | Orcid: https://orcid.org/0000-0001-7253-814X
}

DOI: https://dx.doi.org/10.12795/Ambitos.2020.i49.02

\begin{abstract}
Resumo
Nesse texto, apresentam-se a abordagem teórico-metodológica e alguns resultados da investigação realizada no doutorado em Comunicação, Brasil, que teve como objetivo analisar as apropriações e os sentidos produzidos por crianças acerca das identidades femininas no âmbito da recepção midiática. Partiu-se do pressuposto de que a mídia afeta a construção de subjetividades, intersetadas por modelos de identidades femininas hegemônicas em circulação na sociedade, conforme Queiroz $(2013,2019)$, Louro, Felipe e Goellner (2007), Xavier Filha (2011). Nesse sentido, aportou-se na investigação qualitativa e de campo na perspectiva de Winkin (1998), Minayo (2011), Lopes (2014), Guber (2004, 2011) e transmetodológica (Maldonado, 2013, 2015), que compreendem a realidade na sua multidimensionalidade e interdisciplinaridade, e reconhecem que os sujeitos da investigação estão ativamente imbricados em uma teia de relações que emergem de suas ações. Para a geração de dados, recorreu-se a diversas fontes, como o diário de campo, o questionário, o desenho, a produção de texto, a seleção de imagens na internet e as rodas de conversa. Participaram da investigação dezessete crianças, entre nove e treze anos de idade. Os resultados aqui apreciados correspondem às imagens de mulheres/pessoas selecionadas pelas crianças na internet, via Google e Google Imagens. Preponderaram nas suas escolhas gostos por mulheres/pessoas jovens, brancas, magras, ricas e famosas, em especial
\end{abstract}


cantoras, apresentadoras de televisão e atrizes, nacionais e internacionais. Elas explicitaram ser essas pessoas bonitas, estilosas e de 'boa aparência'. As conclusões indicaram fortes afetações das mídias no reforço de modelos hegemônicos em circulação na sociedade.

\section{Abstract}

This research show the approach based on theoretical-methodological about one research of doctorate degree made in Brazil of Communication with the object of to analyze the appropriations and meanings produced by children about female identities on media recption. It is thought that the media affects the constructions of subjectivities, intersected by models of hegemonic famele identities in society, according to (Queiroz, 2013, 2019), Louro, Felipe e Goellner (2007), Xavier Filha (2011). In this perspective, it is based on a qualitative and field research in the perspective of Winkin (1998), Minayo (2011), Lopes (2014), Guber (2004, 2011), transmethodological (Maldonado, 2013, 2015), that understands the reality in this multidimensionality and interdisciplinarity, and know that the subjects of this research are actively connected in a web relationships that emerge from their actions. The data were built through the several sources, such as the field diary, the questionnaire, the drawing, the text production, some images and conversation wheels. The survey participants were seventeen children, between nine and thirteen years old. The search results are: images of woman or people selected by children on internet through of Google and Google images. Strongly children choose woman/people especially national and international singers, that is, white, thin, riche, and famous people. The conclusion indicate Strong media effects on the reinforcement of hegemonic models in circulation in society.

Palavras-chave: Mídias, Apropriações, Crianças, Identidades femininas, Transmetodologia

Key-words: Media, Appropriations, Children, Female identities, Transmethodology

\section{INTRODUÇÃO}

apresentam-se nesse texto a abordagem teórico-metodológica e alguns resultados da investigação realizada no doutorado em Comunicação na Universidade do Vale do Rio dos Sinos, Brasil, que teve como objetivo analisar as apropriações e os sentidos produzidos por crianças acerca das identidades femininas no âmbito da recepção midiática1. Partiu-se do pressuposto de que a mídia afeta a construção de subjetividades intersetadas por modelos de identidades femininas hegemônicas em circulação (Queiroz, 2013, 2019) e (Louro, Felipe \& Goellner, 2007). 
Não se teve a pretensão de fixar a análise nos discursos midiáticos sobre as crianças, direcionados a mães, pais, educadores etc. que instituem posições de normalidade e diferenças acerca das identidades femininas e do gênero na infância, com falas centradas em concepções adultocêntricas sobre a vida infantil. Pois se as crianças são consideradas sujeitos produtoras de cultura, de acordo com Corazza (2004), Delgado e Muller (2006), e Sarmento e Pinto (1997), há que se escutá-las, conhecer suas escolhas e percepções, ouvi-las acerca de sua condição e de seus posicionamentos sobre as identidades femininas. Portanto, optou-se na investigação por entendê-las a partir de suas produções, de seus conhecimentos, de sua realidade. Concebê-las como atores sociais, construtoras de conhecimento e cultura. Ressalte-se que, historicamente, as crianças foram consideradas um infante (Ariès, 2011), aquele que não sabe falar, com saberes e experiências negligenciadas, silenciadas.

Assim, na investigação, as crianças protagonizaram e expuseram suas escolhas acerca das identidades femininas ".... das possibilidades que lhes são ofertadas e que vão esculpindo suas identidades, das percepções e sentidos que produzem a partir de suas apropriações no contexto da recepção midiática" (Queiroz, 2013, p.15). Assim, partiu-se dos questionamentos: que modelo de mulher/pessoa permeia o gosto das crianças? Que relação têm esses modelos com os que circulam nas mídias? O que as crianças falam acerca desses modelos? Ressaltemos que os modelos de mulheres/pessoas que circulam nas mídias estão relacionados com as produzidas hegemónicamente no seio da estrutura da sociedade contemporânea.

Nessa perspectiva, aportou-se na investigação qualitativa e de campo, na perspectiva de Winkin (1998), Minayo (2011), Guber (2004, 2011), e transmetodológica (Maldonado, 2013, 2015), que compreendem a realidade na sua multidimensionalidade e interdisciplinaridade, e reconhecem que os sujeitos da investigação estão ativamente imbricados em uma teia de relações que emergem de suas ações. Nessa direção, a metodologia de uma investigação não deve se restringir a receituários, mas a processos de tomada de decisões e invenções, pois é no percurso do caminho que se identificam os indícios, as marcas, os rastros e detalhes até a constatação dos fatos, afirma Ginzburg (2009).

Para geração de dados, recorreu-se a diversas fontes, como o Diário de Campo, o questionário, o desenho, a produção de texto, acesso à internet (Google e Redes Sociais) e as rodas de conversa, com participação de dezessete crianças. Foi assim que o conhecimento foi produzido, em movimentos interativos de idas e vindas, do voltar e revisar as decisões tomadas, sem descuidar da acuidade do pensamento crítico-reflexivo, desnovelando os embaraços, contingências e nuances encontradas no seu percurso, afinal é impossível retratar os fatos como aconteceram, já que todos se encontram sempre no meio do caminho ou no caminho do meio das coisas (Queiroz, 2013). 


\title{
2. ABORDAGEM DA INVESTIGAÇÃO: O CAMPO, OS SUJEITOS E A PRODUÇÃO DE DADOS
}

A investigação empírica foi realizada na cidade de Teresina, Piauí, Nordeste do Brasil, com participação de dezessete crianças, entre nove e treze anos de idade2, do sexo feminino, estudantes de escolas públicas e privadas. Elas aderiram voluntariamente à proposta. Pretendia-se contemplar a diversidade do universo infantil quanto à classe social, suas escolhas e atribuições acerca das identidades femininas.

A entrada no campo ocorreu em dois momentos e com grupos distintos de crianças. $O$ primeiro momento ocorreu em 2011, e o segundo, em 2012. No início dos trabalhos realizou-se uma roda de conversa para apresentação dos partícipes e da proposta de investigação. Aproveitou-se o encontro para dialogar com as crianças que propuseram ser identificadas na investigação por codinomes. Perguntou-se, então: se você pudesse ser outra pessoa/mulher agora, quem gostaria de ser? Obtiveram-se as seguintes respostas:

\author{
Isabella Swan3 \\ Carla4 \\ Alice \\ Roberta \\ Rihanna5 \\ Fergie6 \\ Avril Lavigne7 \\ Médica \\ Gretchens \\ Ivete Sangalo9 \\ Shakira 10 \\ Ana11 \\ Maitê Perroni12 \\ Paris Hilton 13 \\ Lady Gaga 14 \\ Kelly Key 15 \\ Ana Hickman 16
}

Os codinomes com os quais as crianças gostariam de ser identificadas revelaram uma forte afetação da mídia, produções da cultura de massa e de entretenimento, como o filme Crepúsculo e a telenovela Rebelde. A maioria se identificou com celebridades nacionais e internacionais da mídia. Foram atrizes, cantoras, modelos e apresentadoras de televisão. Elas explicitaram ser a beleza fonte de inspiração, seguidas da fama e riqueza, características que incidiram diretamente na constituição de suas identidades femininas. Somente duas escolheram pessoas fora do circuito midiático. Uma escolher ser sua melhor amiga, a Ana. A outra, ser médica. 
As respostas sugiram espontaneamente sem que as crianças fossem indagadas a priori sobre personagens midiáticas, explicitando elementos importantes de suas escolhas em relação às identidades femininas. Conforme Fischer (2013), a mídia com todo o aparato da indústria cultural se faz presente no cotidiano da sociedade e na vida das crianças, incidindo na produção de subjetividades e construindo identidades. Imersas na cultura do consumo, que transforma as pessoas em mercadoria (Bauman, 2008), as crianças vão produzindo e reproduzindo identidades hegemônicas, padronizadas e dicotômicas, pois as mensagens midiáticas não vendem apenas produtos, mas valores, ideais e identidades desejáveis que enaltecem a ordem social hegemônica vigente. Ressalte-se que exercer efeitos não é determinar, pois há sempre espaços a serem preenchidos, e isso permite entender as relações de poder, dominação e resistências.

No decorrer da investigação, buscou-se novas evidências acerca da problemática em questão, pois uma das premissas da investigação qualitativa é conhecer como as experiências humanas individuais e coletivas são vividas e descritas pelos seus próprios atores em seus movimentos e escolhas, tornando acessível o particular, já que ".... estudar o social individualizado é estudar a realidade social" (Lahire, 2005, p.14). E, a cada movimento, novas nuanças se colocavam e exigiam mobilização de estratégias novas para os desafios emergentes.

Concorda-se com Guber $(2004,2011)$ que o campo não é dado, mas construído ativamente na relação que se estabelece entre o investigador e os sujeitos da investigação, entre fenômenos observáveis e os significados que os sujeitos dão ao vivido, às suas ações, que integram suas práticas e ideias, seu comportamento e suas representações, e que estão imbricados nas relações de poder e resistências. Na pesquisa qualitativa, o campo não é somente um espaço geográfico e, sim, um espaço de tomada de decisões, observações, escolhas, questionamentos que vão demarcando áreas, envolvendo os sujeitos sociais e interpretando as informações nas processualidades. Uma conjunção que envolve o ambiente físico, sujeitos e atividades.

Assim, aportou-se na abordagem transmetodológica para a construção da investigação que ".... parte da premissa da investigação científica em comunicação precisa da confluência profunda, cooperativa e produtora da estruturação de métodos mistos, múltiplos...." (Maldonado, 2013, pp.720-721). Ela compreende a epistemologia como uma dimensão do conhecimento que incide no conjunto das dimensões teóricas, lógicas, metódicas e técnicas para sua constituição. Essa perspectiva nos coloca na condição de experimentadores e inventores de novas formas de produção qualitativa do conhecimento no campo das Ciências da Comunicação.

Eis aqui o resultado de um experimento investigativo. Nele, afinaram-se os instrumentos de produção de dados, conforme as necessidades advindas do campo, dos sujeitos e do objeto de estudo. As técnicas e instrumentos da investigação foram 
produzidas em processos de construção e reconstrução constantes, em movimento imbricado entre a investigadora e as crianças partícipes da investigação (Queiroz, 2013), conforme diagrama a seguir:



Figura 1. Técnicas de produção de dados da investigação Fonte: Queiroz, 2013

Utilizou-se o diário de campo, conforme Winkin (1998), para descrever os acontecimentos ocorridos no campo à procura de indícios que evidenciassem a presença do midiático no comportamento e nas falas das crianças. O diário de campo foi importante no registro das experiências vivenciadas com as crianças e permitiu a rememoração das ações naqueles momentos específicos de encontros.

Outra técnica desenvolvida com as crianças foi a entrevista semiestruturada, que, no entanto, não foi exitosa. Nas entrevistas, as crianças se mostravam inquietas, ansiosas e sem disposição para responder às perguntas formuladas, reafirmando o que observam Rocha e Campos (2008) sobre a dificuldade da utilização desse tipo de técnica com o público infantil, pois as crianças são objetivas no diálogo que estabelecem. E, se a intenção era deixar a criança à vontade, as atividades propostas deviam acompanhá-las em seus tempos, espaços, falas e comportamentos.

Prescindiu-se, então, da entrevista e propôs-se o questionário, na perspectiva de capturar o perfil socioeconômico das crianças e mapear seu consumo midiático, os seus gostos e preferências. O questionário foi elaborado a partir das sugestões de algumas crianças e respondido individualmente em encontros realizados na própria escola. A vantagem de utilizar esse instrumento, como enfatiza Gil (2008), é a objetividade das perguntas, e isso proporcionou respostas assertivas e rápidas por parte das crianças. 
Utilizou-se, também, o recurso da produção do desenho, momento em que as crianças desenharam pessoas/mulheres que gostariam ou não de ser. Em outro momento, solicitou-se que desenhassem uma pessoa/personagem preferida da mídia. Uma folha de papel foi entregue às crianças. De um lado da folha havia espaço para a escrita do desenho e, do outro, para a justificativa da sua escolha. Em concordância com Gobbi (2009), o desenho revela olhares e concepções das pessoas, em específico das crianças, sobre seu contexto social, histórico e cultural, pensados, vividos e desejados. O desenho, como toda linguagem, é expressão e marca das condições socioculturais dos sujeitos, suas vivências, experiências, necessidades e desejos. Outra técnica utilizada foi a produção de textos, momento em que expressaram seu entendimento/concepção sobre ser mulher, o que revelou aspectos novos de suas escolhas e de suas compreensões a respeito das identidades femininas.

Em seguida, realizou-se a atividade de acesso a internet. Ressalte-se que as crianças, desde o início da investigação, questionavam: "Professora, quando nós vamos para o laboratório de informática entrar na internet?" Inicialmente, não havia o propósito de utilizar a internet como técnica de investigação, mas à medida em que as crianças expressaram o desejo, revelou-se necessário incorporá-la na investigação. $O$ acesso à internet ocorreu em dois momentos. No primeiro, as crianças acessaram a internet livremente, sem encaminhamentos, momento em que revisitaram e/ou criaram perfis nas redes sociais. No segundo, foi solicitado que selecionassem uma imagem de pessoa/mulher que gostariam de ser e uma que não gostariam de ser, uma imagem de mulher que considerava bonita e uma imagem de mulher que não considerava bonita.

No decorrer da investigação, realizaram-se momentos de socialização das produções, em rodas de conversa, cujo pressuposto central foi a partilha de ideias por meio do diálogo e a construção de novos conhecimentos críticos e modos de ação, pois sabese é a partir do embate e das contradições que se constroem novos significados sobre as experiências de vida (Warschauer, 1993). Nelas, apresentou-se as escolhas das crianças que observavam atentamente e manifestavam suas percepções no coletivo, concordando ou discordando.

As técnicas e os instrumentos de geração de dados foram pensados a partir do grupo de crianças com o qual estávamos interagindo, o espaço institucional da escola em que nos situávamos e do recorte teórico-metodológico realizado (Queiroz, 2013). Foram vários os retornos ao campo, na busca de ampliar os horizontes sobre 0 fenômeno investigado.

\section{CONSUMINDO IDENTIDADES FEMININAS NO GOOGLE}

Os resultados da investigação, apresentados nesse item, são relativos à atividade de acesso das crianças à internet, em específico no Google e Google Imagens. Sabe-se que o Google é uma das ferramentas de buscas mais conhecidas e acessadas na 
atualidade. O Google, que nasceu na década de 1990, estabelece-se, de acordo com Fragoso (2007), no final do ano de 2000:

Como o melhor sistema de buscas na mente do público. Os demais buscadores foram obrigados a encarar a superioridade da relevância dos resultados fornecidos pelo Google e a lealdade que aquela qualidade gerara entre os usuários: muitos outros sistemas de busca, inclusive alguns grandes como o Yahoo!, fariam acordos para incluir resultados vindos do Google em suas próprias páginas. Ao final de 2003, chegou-se a estimar que dois terços de todas as buscas realizadas na web retornavam resultados oriundos do Google. (p. 9)

A autora, afirma ainda, que na internet há milhares de sites de buscas e que as páginas indexáveis, conteúdo da web normalmente acessível às ferramentas de busca, cresceram de 800 milhões, em 1999, para 11,5 bilhões, em 2005. Os buscadores funcionam como gatekeeps digitais, como filtros que operam com objetivos comerciais. O que reitera a escolha das crianças pelo Google e Google Imagens com ferramentas de buscas. O primeiro grupo, com oito crianças, acessou com a seguinte pergunta: Que mulher/pessoa você gostaria de ser? (imagens de 1 a 8). O segundo grupo, com nove crianças, acessou com a pergunta: Que pessoa bonita você escolhe, gostaria de ser? (imagens de 9 a 17).

As imagens capturadas pelas crianças estão circulando livremente na internet. Questiona-se: são imagens capturadas pelas crianças? Ou crianças capturadas pelas imagens? Optou-se, por analisar o conjunto das imagens, conforme apresentadas a seguir:

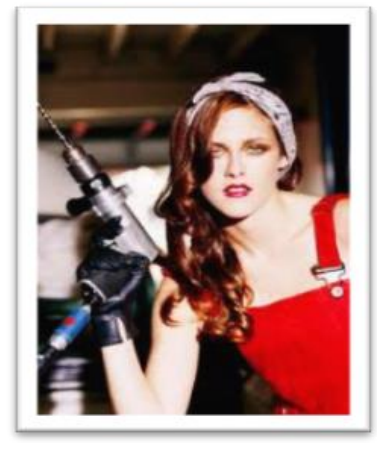

A criança com codinome Isabella Swan escolheu na internet ser ela novamente. Ao ser indagada sobre sua escolha, explicitou que: "Tem um corpo bonito", "Tem um namorado muito gato", "Ela é famosa".

Imagem 1 - Isabella Swan 


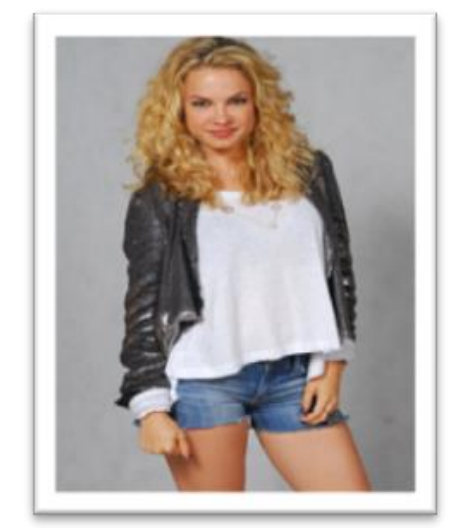

Imagem 2 - Roberta

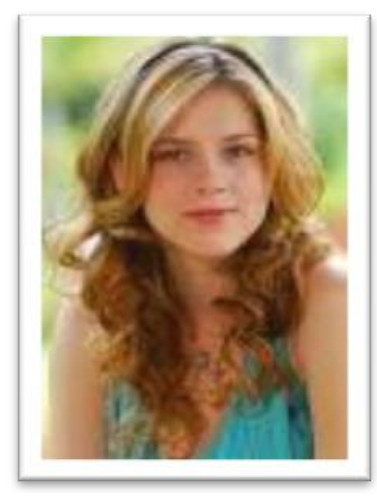

Imagem 3 - Alice

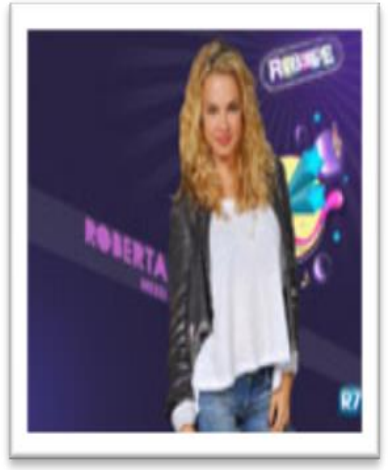

Imagem 4 - Roberta
A criança com codinome Carla escolheu na internet ser Roberta. Ao ser indagada sobre sua escolha, relatou que: "Ela é muito bonita", "Ela é inteligente e carinhosa (disse que retirou do perfil da atriz na internet essas últimas características)".

A criança com codinome Alice escolheu na internet ser ela novamente. Ao ser indagada sobre sua escolha, esclareceu que: "Por que ela é uma 'quase' mulher, bonita, muito batalhadora e corre atrás do que quer", "Gosto dela por que é linda e loira".

A criança com codinome Roberta escolheu na internet ser ela novamente. Ao ser indagada sobre sua escolha, explicitou que: "Ela é bonita, magra e engraçada", "Ela é romântica e alegre", "Ela está namorando o Diego (personagem da Telenovela Rebelde que namora Roberta) e, por isso, gosto dela". 


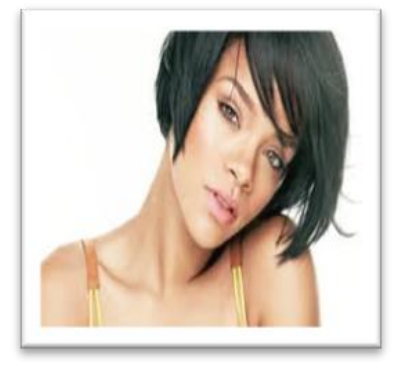

Imagem 5 - Rihanna

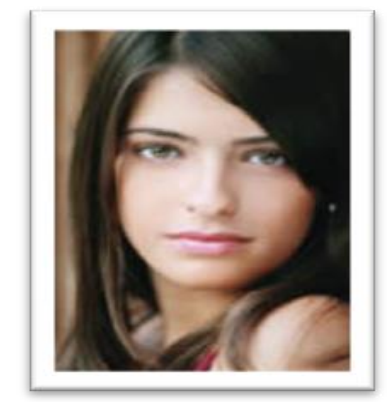

Imagem 6 - Débora

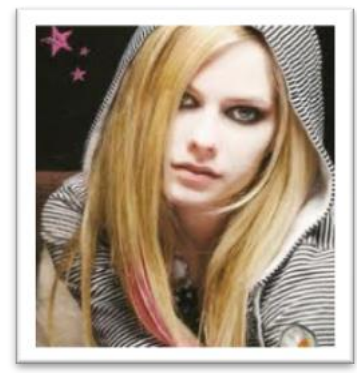

Imagem 7 - Avril Lavigne

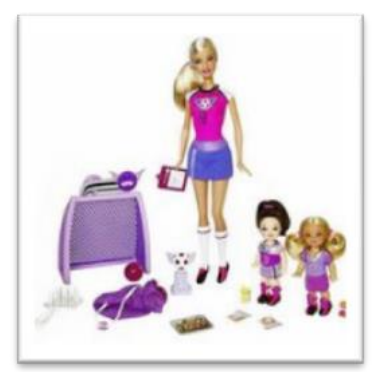

Imagem 8-Barbie

A criança com codinome Rihanna escolheu na internet ser ela novamente. Ao ser indagada sobre sua escolha, esclareceu que: Ela é bonita, estilosa, tem os olhos claros e canta bem", "As suas músicas são ótimas e dá até para chorar".

A criança com o codinome Fergie escolheu na internet ser Débora17. Ao ser indagada sobre sua escolha, falou que: "Esta mulher é bonita", "Ela tem boa atuação na mídia".

A criança com o codinome Avril Lavigne escolheu na internet ser ela novamente. Ao ser indagada sobre sua escolha, referiu que: "Ela tem estilo", "Ela é bonita", "Ela canta bem".

A criança com codinome Médica escolheu na internet ser Barbie 18 esportista. Ao ser indagada sobre sua escolha, explicitou que: "Ela também tem sua profissão", "Ela é muito bonita e delicada".

Entre as oito crianças, apenas uma escolheu ser a Barbie (uma boneca adolescente). A maioria escolheu mulheres adultas, jovens, magras e brancas; e apenas uma criança escolheu ser uma mulher negra, Rihanna, mas enfatiza que é bonita porque 
"tem olhos claros". Ressalte-se que as mulheres escolhidas atuam nas mídias. São atrizes de filmes e de telenovelas, cantoras, e a boneca Barbie. Para as crianças essas mulheres foram escolhidas especialmente porque são bonitas "loira, olhos claros, magra, delicada, romântica, alegre, inteligente, batalhadora"; são famosas, têm boa profissão, cantam bem, têm namorado, são famosas e estilosas. A aparência física foi ponto de referência nas escolhas das crianças.

Aqui, percebe-se a figura da "supermulher" - as profissionais e belas. São "cantoras e atrizes famosas', com visibilidade pública e bem-sucedidas. E que devem manter, ao mesmo tempo e como por encanto, a competência, a beleza. São mulheres loiras, olhos claros, magras; a buscar; loira, olhos claros, magra; a busca do namorado, a delicadeza e o romantismo das princesas, que delineiam historicamente o ideal de feminilidade, como enfatiza Xavier Filha (2011).

Ser bela foi uma dimensão que apareceu na totalidade das escolhas das crianças do primeiro grupo de investigação. Assim, decidiu-se também as realizar com o segundo, com ênfase na palavra "pessoas" em vez de "mulher", com vistas a englobar a diversidade de possibilidades de identidades femininas, os diferentes grupamentos sociais assim como entender os "enquadramentos" para além dos modelos binários de identidades.

A seguir apresentam-se as imagens selecionadas individualmente, por cada criança partícipe do segundo grupo, e questionadas coletivamente nas rodas de conversa, momento em que as imagens foram expostas em slides, uma a uma, para que se lhes indagasse: 1) O que vocês acham dessas pessoas? 2) O que o grupo de pessoas bonitas têm em comum? 3) Quem gostaria de ser essa pessoa? 4) Pode-se chegar a que conclusão sobre o grupo escolhido?



Imagem 9- não conhecia o nome
A criança com codinome Gretchen escolheu na internet ser essa pessoa (não conhecia o nome). Ao ser indagado, o grupo explicitou também ser essa pessoa bonita porque: "Ela é atriz", "É loira e seus cabelos são longos e lisos", "É magra, branca, tem 'peitão' e é elegante", "Mas ela não parece ser educada, pois tem cara de safada", "Não parece ser rica". Das nove crianças, sete escolheram ser essa pessoa. 


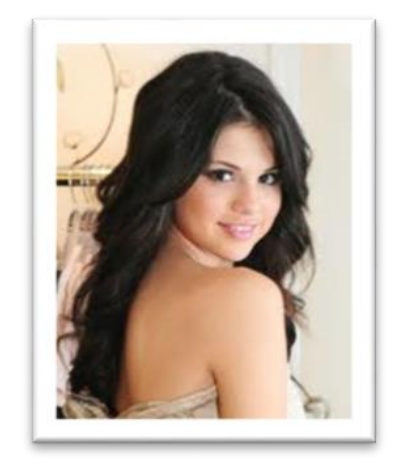

Imagem 10 - Selena Gomez



Imagem 11 - não conhecia o nome



Imagem 12 - não conhecia o nome
A criança com codinome Ivete Sangalo escolheu na internet ser Selena Gomez19. Ao ser indagado, o grupo explicitou também ser essa pessoa linda porque: "É atriz, cantora e exnamorada do Justin Bieber", "Tem olhar sedutor", "Tem os cabelos lindos", "Parece ser rica", "Mas ela não parece ser educada, tem o nariz empinado". Das nove crianças, seis escolheram ser essa pessoa.
A criança com codinome Shakira escolheu na internet ser essa pessoa (não conhecia o nome). Ao ser indagado, o grupo explicitou também ser essa pessoa linda porque: "Tem olhos verdes e a boca bonita", "Parece uma atriz de cinema", "Aparenta ser educada, uma santinha". Das nove crianças, oito escolheram ser essa pessoa.

A criança com codinome Ana escolheu na internet ser essa pessoa (não conhecia o nome). Ao ser indagado, o grupo explicitou também ser essa pessoa bonita porque: "Tem olhos verdes e cabelos bonitos", "Tem a pele bonita e os lábios carnudos", "Aparenta ser educada". Das nove crianças, sete escolheram ser essa pessoa. 


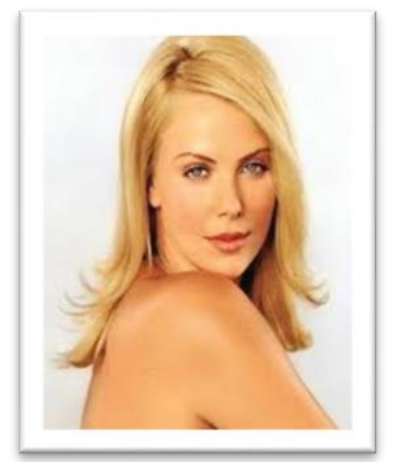

Imagem 13 - não conhecia o nome
A criança com codinome Maitê Perroni escolheu na internet ser essa pessoa (não conhecia o nome). Ao ser indagado, o grupo explicitou também ser essa pessoa linda porque: "É linnnnnnnnnnnda20", "É perfeita, seus olhos são cor de mel”, "É atriz", "Tem boa aparência e parece ser educada". Das nove crianças, oito quiseram ser essa pessoa.

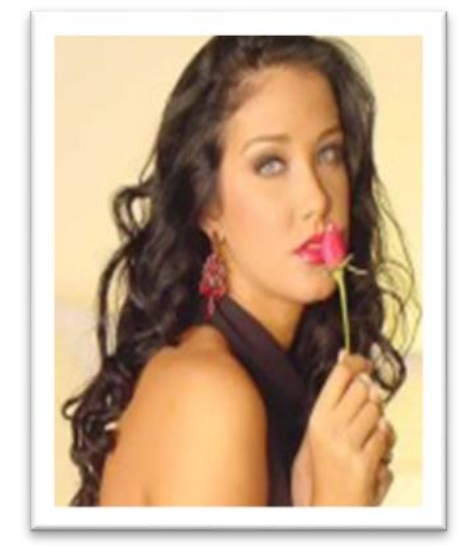

Imagem 14 - Helen Ganzarolli

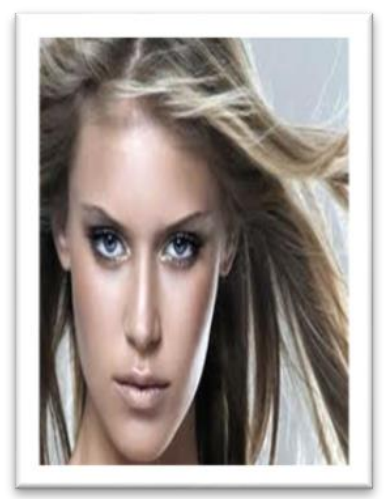

Imagem 15 - não conhecia o nome
A criança com codinome Paris Hilton escolheu na internet ser essa pessoa Helen Ganzarolli21. Ao ser indagado, o grupo explicitou também ser essa pessoa linda e maravilhosa porque: "Ela é atriz e dançarina", "Ela tem olhar sedutor", "Ela é rica e famosa, e tem um marido rico e cantor", "O apresentador de televisão, Sílvio Santos, gosta dela", "Mas parece não ser educada". Das nove crianças, sete quiseram ser essa pessoa.
A criança com codinome Lady Gaga escolheu na internet ser essa pessoa (não indicou o nome). Ao ser indagado, o grupo explicitou também ser essa pessoa bonita22 porque: "Ela tem cabelos lisos e loiros", "Ela tem olhos e sobrancelhas perfeitas", "Mas parece não ser educada", "Mas parece ser também vingativa". Das nove crianças, seis escolheram ser essa pessoa. 

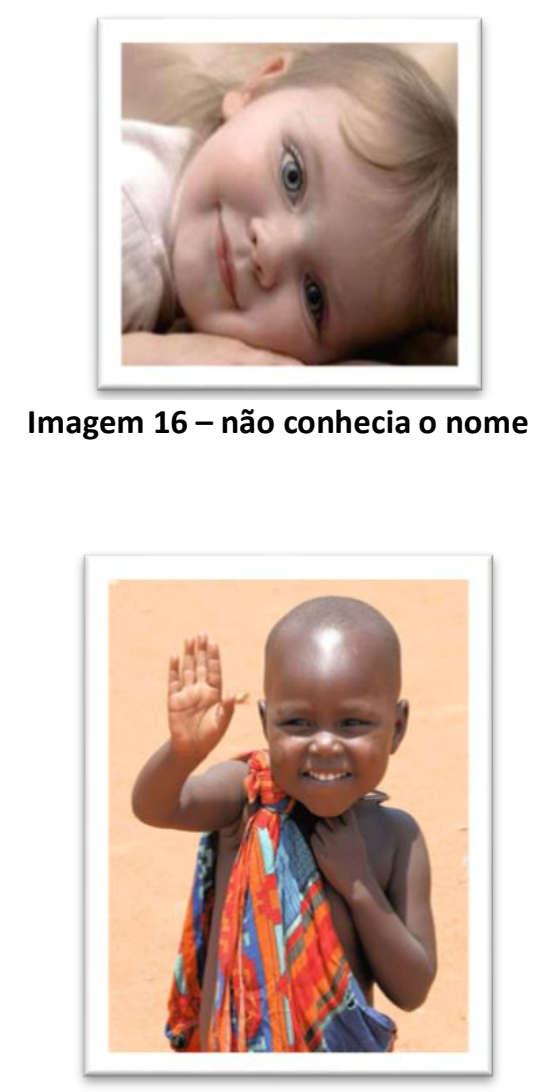

A criança com codinome Kelly Key escolheu na internet ser essa pessoa (não indicou o nome). Ao ser indagado, o grupo explicitou também ser essa pessoa linda porque: "E linnnnnnnnnnnnnnnnda" (unânimes), "Parece uma boneca", "Não parece ser danada", "Tem boa aparência". Das nove crianças, nove escolheram ser essa pessoa.
A criança com codinome Ana Hickman escolheu na internet ser essa pessoa (não indicou o nome). Ao ser indagado, o grupo teve dúvidas e dificuldades em concordar com a escolha. Algumas crianças, entre elas a própria Ana Hickman, manifestaram que: "Ele é da África e passa fome", "Ele é humilde e tem dentes perfeitos". Outras manifestaram que: "Ele não aparenta passar fome, pois é gorducho e sorridente". Entre elas: cinco falaram que: "ele é fofinho, mas aparenta ser danado". Duas que ele: "não é bonito", mas não comentaram suas posições. Outras duas que: "ele é engraçadinho". Das nove crianças, apenas duas quiseram ser essa pessoa.

Imagem 17 - não conhecia o nome

No segundo grupo, há identificações distintas do primeiro, a exemplo das duas imagens de crianças, entre elas uma negra. Houve vários questionamentos entre as crianças quando apresentada a imagem da criança negra, emergindo uma polêmica em torno de sua beleza. A criança que a escolheu questionou suas colegas sobre suas escolhas serem somente mulheres brancas e adultas. Ela e sua amiga tinham escolhido crianças, sendo ela a única que escolhera uma pessoa negra, e que em outras atividades ela escolhera também mulher adulta e branca, mas atentou para esse fato, quando acessou no Google imagens "pessoas bonitas" e só encontrou pessoas brancas e adultas; e que, ao acessar pessoas que não são bonitas (feias), apareciam, em sua maioria, pessoas negras, pobres, esquisitas. Por isso, fez a busca em "crianças negras bonitas", escolhendo o menino negro.

O grupo de crianças, ao comentar sobre a escolha da criança negra, nem percebeu que na imagem a criança mostrava-se feliz, com saúde e bem-vestida. No imaginário delas, a criança negra foi associada a um contexto geográfico específico - África, e a uma determinada classe social - a pobre. É importante explicitar que não havia no site ou na própria imagem nenhuma informação sobre o local de origem da criança. 
Entre as pessoas/mulheres, as crianças escolheram, em sua maioria, ser atrizes, cantoras, apresentadoras de televisão e outras que não foram identificadas. Elas foram descritas como bonitas, com exceção da criança negra, que tiveram dificuldades em aceitá-lo como uma pessoa bonita. São pessoas/mulheres jovens, magras, brancas, cabelos longos, lisos e olhos claros. Ser branca e rica são qualidades que ainda imperam na sociedade e servem de referências na construção de identidades que permeiam o imaginário das crianças.

Outro aspecto importante a considerar aqui se refere à fama. Oito crianças escolheram celebridades visibilizadas cotidianamente na mídia. O que se observou é que ser bela, rica e famosa constituíram características fundamentais nas suas escolhas. Atuar na mídia de massa e se tornar uma profissional famosa e reconhecida é a principal expectativa que as crianças evidenciaram. De um contexto em que as clássicas princesas alimentavam os sonhos infantis, as crianças hoje passam a colecionar celebridades, momentâneas ou não, que surgem das corporações que fabricam brinquedos infantis, da moda, dos filmes, das novelas, da música, conforme Steinberg e Kincheloe (2004).

Além do perfil descrito, as crianças indicaram a educação e a moral como características importantes. Para elas, as pessoas/mulheres com aparência de "cara de safada", "nariz empinado", "olhar sedutor" e "vingativa" não são educadas. E as com aparência de "santinha", "perfeitas", "simplesmente bonitas", "boa aparência" e "que não são danadas", são educadas.

Coaduna-se uma multiplicidade de identidades femininas, a mulher santa, de comportamento recatado, delicada e discreta. Além de "recatadas" devem ser belas, educadas e ricas. Os padrões de beleza e de comportamentos manifestos pelas crianças centram-se em determinados perfis hegemônicos que são considerados "adequados" e aceitos socio-culturalmente.

É importante considerar que, na contemporaneidade, os conceitos e os significados atribuídos a alguém são construídos por um conjunto de imagens e de discursos que se apresentam, provocando identidade ou rejeição. Assim, pode-se afirmar que, ao constituir uma rede de sentido que envolve os indivíduos, em especial as crianças, a mídia tenta conformar culturalmente o seu público por meio de seus discursos e suas imagens interpelativas. Ser branca, magra, alta, rica e famosa faz parte da norma que impera na sociedade e referencia ser bonita, ter sucesso. É claramente perceptível que a mídia preponderantemente veiculará tais modelos e concepções. Os diferentes desse padrão, os outros, são nomeados como diferentes, estranhos e deslocados, afirmam Hall (2003) e Silva (2003).

Ressalte-se que as crianças estão imersas na "nação de consumidores" (Canclini, 2010), consumindo cotidianamente modos de ser e estar no mundo, modelos de 
pessoas e comportamentos sociais que vão colaborando na constituição de suas identidades e subjetividades. Nela, a mídia torna-se sua aliada, na medida em que penetra no imaginário e aguça os seus desejos, individualmente e coletivamente.

\section{CONCLUSÕES}

No processo de construção da investigação sempre se manteve uma relação dialógica e reflexiva com as crianças. Escutavam-se as crianças (ao tempo que a pesquisadora se escutava), procurando seguir os ritmos, os anseios e as necessidades advindas da investigação. Elas indicavam alternativas metodológicas, opinavam e/ou rejeitavam algumas atividades propostas. O que nos levou a refletir constantemente sobre ações, relações e comportamentos no desenvolver da investigação. A investigação inovou em algo - acredito nisso - e certamente foi no tocante aos sujeitos da investigação - as crianças.

Os dados produzidos evidenciaram uma forte interligação entre os modelos hegemônicos que circulam na sociedade e os veiculados na internet, e que estão entranhadas nas suas experiências de vida das crianças numa dialética de acomodações e resistências. As identificações das crianças comportaram uma diversidade de modelos e concepções, definidas nas seguintes categorias:

\begin{tabular}{|c|c|c|c|c|}
\hline \multicolumn{5}{|c|}{ MÚLTIPLAS IDENTIDADES FEMININAS } \\
\hline \multirow{2}{*}{$\begin{array}{c}\text { Estética } \\
\text { (boa } \\
\text { aparência): } \\
\text { bonita, jovem, } \\
\text { magra, loira, } \\
\text { branca, olhos } \\
\text { claros/verdes. }\end{array}$} & \multirow{2}{*}{$\begin{array}{l}\text { Educada: } \\
\text { alegre, } \\
\text { carinhosa, } \\
\text { delicada, } \\
\text { romântica, } \\
\text { ter marido. }\end{array}$} & $\begin{array}{l}\text { Papéis } \\
\text { sexuais }\end{array}$ & \multirow{2}{*}{$\begin{array}{l}\text { Profissional: } \\
\text { Inteligente, } \\
\text { batalhadora, } \\
\text { trabalhadora. }\end{array}$} & \multirow{2}{*}{$\begin{array}{l}\text { Classe } \\
\text { social: } \\
\text { Rica, } \\
\text { famosa, } \\
\text { estilosa }\end{array}$} \\
\hline & & $\begin{array}{r}\text { Mal-ec } \\
\text { Sa } \\
\text { sed } \\
\text { ving } \\
\text { arro }\end{array}$ & & \\
\hline
\end{tabular}

Figura 2. Identificações femininas das crianças Fonte: Queiroz, 2013

As identificações ora se acomodaram de modelos hegemônicos, com ênfase na moral cristã e patriarcal, interseccionados pelos papéis sexuais, estéticos e classe social, e ora se afastaram desses modelos numa ação de resistência, num movimento crítico e emancipatório, ao mencionar aspectos como inteligência e profissionalismo da mulher.

É importante conceber que essas posições foram produzidas a partir das experiências, dos saberes e das informações consumidas, traduzidas e reconstruídas no âmbito da recepção midiática como afirmam Orozco (2011), Queiroz e Cogo (2014). Portanto, é importante a introdução de novas experiências e formas de pensar coletivos que visem 
romper com as estruturas opressoras da sociedade patriarcal e suas armadilhas como diz Anyon:

A armadilha as prende porque a acomodação e a resistência não buscam remover as causas estruturais das contradições. Para tal transformação, as mulheres necessitam realizar uma ação coletiva. Isto significa dizer que, enquanto a acomodação e resistência - como modos cotidianos de atividades oferecem às mulheres caminhos para negociarem individualmente o sentimento social de conflito ou opressão, esta atividade individual cotidiana fica apenas nisto: individual, fragmentada e isolada dos esforços grupais; portanto, politicamente enfraquecida... (1990, p.23)

\section{Notas}

[1] A recepção passou a ser o lugar da investigação e não apenas como uma área de investigação sobre mais um dos polos que compõem o processo de comunicação, ou um momento do ato de comunicação, e sim como uma perspectiva entranhada à produção e ao consumo, conforme Lopes (1999, 2014), Orozco (2011), Canclini (2010). Uma complexa rede de relações permeada de contradições e conflitos, poder e resistência. Um campo de produção e reprodução social dos sentidos envolvidos nos processos culturais, e que não se restringem apenas uma questão de sentidos, mas principalmente de poder (Moraes, 2016).

[2] Os pais, mães e/ou responsáveis consentiram a participação das crianças na investigação. A investigação foi aprovada no Comitê de Ética da UNISINOS.

[3] Isabella Swan (personagem principal do filme Crepúsculo, veiculado no Brasil em dezembro de 2008, inspirado em livro homônimo).

[4] Carla (personagem adolescente da telenovela Rebelde, versão brasileira, veiculada pela emissora Record, desde março de 2011, e que faz parte de uma banda de música, junto com Alice e Roberta. A emissora SBT veicula a versão mexicana).

[5] Rihanna (cantora caribenha, nascida na ilha de Barbados).

[6] Fergie (cantora estadunidense, nascida em Los Angeles).

[7] Avril Lavigne (cantora canadense, denominada princesa do pop punk.

[8] Gretchen (cantora e dançarina brasileira, nascida no Rio de Janeiro, e iniciou sua carreira na década de 1970).

[9] Ivete Sangalo (cantora brasileira, nascida na Bahia).

[10] Shakira (cantora colombiana, nascida na cidade de Barranquilla).

[11] Ana (sua melhor amiga).

[12] Maitê Perroni (personagem adolescente na telenovela Rebelde, versão mexicana. Atua também como cantora).

[13] Paris Hilton (socialite estadunidense, nascida em Nova lorque).

[14] Lady Gaga (cantora estadunidense, nascida em Nova lorque).

[15] Kelly Key (cantora, dançarina e apresentadora brasileira, nascida no Rio de Janeiro).

[16] Ana Hickman (modelo e apresentadora brasileira, nascida no Rio Grande do Sul).

[17] Débora (personagem do seriado Malhação, veiculado pela emissora Globo, e também da 
telenovela Rebelde, versão brasileira, veiculada pela emissora Record).

[18] O sucesso da boneca Barbie está atrelado à beleza e a um comportamento jovem e consumista. De descendência alemã é fruto de um modelo feminino ideal do pós-guerra: respeitável, educada e elegante (Lord, 2004).

[19] Selena Gomes (atriz e cantora estadunidense).

[20] Houve empolgação das crianças ao visualizar essa pessoa. Foram unânimes ao achar essa pessoa linda.

[21] Helen Ganzarolli (apresentadora da emissora SBT e modelo brasileira.)

[22] Uma parte do grupo ficou em dúvida em relação à beleza dessa pessoa, pois acharam o rosto dela fino demais, esquisito.

\section{Referências}

Anyon, J. (1990). Interseções de gênero e classe: acomodações e resistência de mulheres e meninas às ideologias de papéis sexuais. Cadernos de Pesquisa, 73, 13-25. Recuperado de https://bit.ly/2RsDj94

Ariès, P. (2011). História social da criança e da família (2a ed.). Rio de Janeiro, Brasil: LTC.

Bauman, Z. (2008). Vida para o consumo: a transformação das pessoas em mercadorias. Rio de Janeiro, Brasil: Zahar.

Campos, M. M. (2008). Por que é importante ouvir a criança? A participação das crianças pequenas na científica. In: S. H. V. Cruz (Org.). A criança fala: a escuta de crianças em investigações qualitativas (pp. 35-42). São Paulo, Brasil: Cortez.

Canclini, N. G. (2010). Consumidores e cidadãos: conflitos multiculturais da globalização. Rio de Janeiro, Brasil: UFRJ.

Corazza, S. M. (2004). A história da infância sem fim (2a ed.). ljuí, Brasil: UNIJUÍ

Delgado, A.C.C., \& Muller, F. (2006, janeiro a junho). Infâncias, tempos e espaços: um diálogo com Manuel Jacinto Sarmento. Currículo Sem Fronteiras, (6)1, 15-24. Recuperado em https://bit.ly/3b2zOy3

Fischer, R. M. B. (2013). Televisão \& Educação: fruir e pensar a TV. Belo Horizonte, Brasil: Autêntica.

Fragoso, S. (2007, setembro a dezembro). Quem procura, acha? O impacto dos buscadores sobre o modelo distributivo da World Wid Web. Revista de Economia Política de las Tecnologías de la Información y Comunicación, (9)3. Recuperado em https://bit.ly/2Rtj7Eq

Gil, A. C. (2008). Métodos e Técnicas de Investigação Social. São Paulo, Brasil: Atlas.

Ginzburg, C. (2009). Mitos, Emblemas e Sinais: morfologia e história. São Paulo, Brasil: Companhia das letras. 
Gobbi, M. (2009). Desenho Infantil e oralidade: instrumentos para investigações com crianças pequenas. In: A. L. G. Faria, Z. B. F. Demartini, \& P. D. Padro (Orgs.). Por uma cultura da infância: metodologia de investigação com crianças (3a ed., pp.69-92). Campinas, Brasil: Autores Associados.

Guber, R. (2004). El salvaje metropolitano: reconstrucción del conocimiento social em el trabajo de campo. Buenos Aires, Argentina: Paidós.

Guber, R. (2011). La etnografía, método, campo y reflexividad. Buenos Aires, Argentina: Siglo Veintiuno Editores.

Hall, S. (2003). Quem precisa de identidade. In: T. T. Silva (Org.)., S. Hall \& K. Woodward. Identidade e diferença: a perspectiva dos estudos culturais (pp.103-133). Petrópolis, Brasil: Vozes.

Lahire, B. (2005). Patrimónios individuais de disposições: Para uma sociologia à escala individual. Sociologia, Problemas e Práticas, 49, 11-42. Doi: https://doi.org/10.1017/CBO9781107415324.004. Recuperado em https://bit.ly/2RtS77u

Lopes, M. I. V. (1999). Investigação em comunicação: formulação de um modelo metodológico. São Paulo, Brasil: Loyola.

Lopes, M. I. V. (2014). Mediação e recepção. Algumas conexões teóricas e metodológicas nos estudos latino-americanos de comunicação. Matrizes, 1, 65- 80 . Doi: http://dx.doi.org/10.11606. Recuperado em https://bit.ly/2VgX9Fy

Lord, M. G. (2004). Forever Barbie - The unauthorized biography of a real doll. New York, EUA: Walker \& Company.

Louro, G. L., Felipe, J., \& Goellner, S. V. (2007). Corpo, Gênero e sexualidade: um debate contemporâneo sobre educação. Petrópolis, Brasil: Vozes.

Maldonado, A. E. (2013). A perspectiva transmetodológica na conjuntura de mudança civilizadora em inícios do século XXI. In: A. E. Maldonado, J. A. Bonin, \& N. M. Rosário (orgs.). Perspectivas metodológicas em comunicação: novos desafios na prática investigativa (pp.31-57). Salamanca, Espanha: Comunicación Social Ediciones y Publicaciones.

Maldonado, A. E. (2015, setembro e dezembro). Transmetodologia, cidadania comunicativa e transformação cultural. Intexto, 34, 713-727. Doi: http://dx.doi.org/10.19132/18078583201534.

Moraes, D. (2016). Por uma outra comunicação: mídia, mundialização cultural e poder. Rio de Janeiro, Brasil: Record.

Orozco, G. (2011). La condición comunicacional contemporánea. Desafíos latinoamericanos de la investigación de las interacciones en la sociedad red. In: N. Jacks (Org.). Analisis de recepición en América Latina: um recuento histórico com perspectiva al futuro (pp.377408). Quito, Ecuador: Quipus/CIESPAL. Recuperado em https://bit.ly/3a3gDTs 
Queiroz, M. M. A. (2013). Eu não quero ser a mulher saliente! Eu prefiro ser a Isabella Swan! Apropriações das identidades femininas por crianças na recepção midiática. (Tese de Doutorado). Universidade do Vale do Rio dos Sinos, Rio Grande do Sul, Brasil. Recuperado em https://bit.ly/2XqRb7D

Queiroz, M. M. A., \& Cogo, D. (2014). As identidades femininas e a recepção midiática de crianças de escolas públicas e privadas. In: Ronsini, V. M., Cogo, D., \& Repoll, J. (Coord.). Estudos de recepção Latino-Americanos: métodos e práticas (pp.158-172). Bellaterra: Institut de la Comunicació, Universitat Autònoma de Barcelona. Recuperado em https://bit.ly/2RsUvvn

Queiroz, M. M. A. (2019). Pesquisa com crianças na Comunicação: um relato de experiência (Trabalho apresentado no Congresso de Investigação Qualitativa em Ciências Sociais, CIAIQ, Lisboa, Portugal, 3, (pp. 489-498). Recuperado em https://bit.ly/2JXTirD

Rocha, E. A. C. (2008). Por que ouvir as crianças? Algumas questões para um debate científico multidisciplinar. In: S. H. V. Cruz (Org.). A criança fala: a escuta de crianças em investigações qualitativas (pp. 43-51). São Paulo, Brasil: Cortez.

Sarmento, M.J. \& Pinto, M. (coords.). (1997). As crianças: contextos e identidades. Braga, Portugal: Universidade do Minho.

Silva, T. T. (Org.). (2003). Identidade e diferença: a perspectiva dos estudos culturais. Petrópolis, Brasil: Vozes.

Steinberg, S., \& Kincheloe, J. L. (Org.). (2004). Cultura infantil: a construção corporativa da infância. Rio de Janeiro, Brasil: Civilização Brasileira.

Warschauer, C. (1993). A roda e o registro: uma parceria entre professor, alunos e conhecimento. Rio de Janeiro, Brasil: Paz e Terra.

Winkin, Y. (1998). A nova comunicação: da teoria ao trabalho de campo. Campinas, Brasil: Papirus.

Xavier Filha, C. (2011). Era uma vez uma princesa e um príncipe...: representações de gênero nas narrativas de crianças. Revista Estudos feministas [online]. (19). 591-603. Doi: https://doi.org/10.1590/S0104-026X2011000200019. 